\title{
Treatment with cimetidine of atypical fasciitis panniculitis syndrome
}

\author{
J E Naschitz, D Yeshurun, I Rosner, J E Abrahamson, I Misselevitch, J H Boss
}

\begin{abstract}
Three patients presented with septal fasciitis and panniculitis, associated with clinical and laboratory features which precluded straightforward classification into eosinophilic fasciitis, localised scleroderma, or lupus erythematosus profundus. Treatment with cimetidine caused the remission of cutaneous manifestations and the extracutaneous abnormalities, such as nailfold capillary disturbances and the presence of antithyroid antibodies, improved.

It is concluded that features of eosinophilic fasciitis or localised scleroderma and certain additional atypical elements should be categorised as atypical fasciitis-panniculitis syndrome.
\end{abstract}

Septal fasciitis associated with panniculitis is a common feature of localised scleroderma, lupus erythematosus profundus, and eosinophilic fasciitis. ${ }^{1}$ Although the latter disorders have been well characterised their pathogenetic mechanisms are elusive and their distinction is based on descriptive rather than strict diagnostic criteria; overlapping features are common. ${ }^{2}$

We describe three patients, who, in addition to similar and distinct fasciitis and panniculitis, featured diverse extracutaneous symptoms. The clinical presentation and laboratory findings in the individual patients did not fall into any of the well known fasciitis-panniculitis disorders.

Patients and methods

Three patients with what we termed atypical fasciitis and panniculitis syndrome (AFPS) were treated in our department over three years. A patient was defined as having AFPS when the following criteria were met: $(a)$ an illness resembling either eosinophilic fasciitis, localised scleroderma, or lupus erythematosus profundus was associated with additional features of a collagen-vascular disease or a vasculitic disorder; (b) histological examination disclosed a primarily septal fasciitis and panniculitis. ${ }^{1-5}$ Infectious and paraneoplastic fasciitides were excluded. ${ }^{4-6}$ Laboratory findings, being non-specific, were not included among the criteria. Microscopic examination of nailfold capillaries was performed using previously described techniques. ${ }^{78}$ Cimetidine, given orally in a daily dose of $800 \mathrm{mg}$, was continued up to the time of writing. The relevant clinical and laboratory data on the patients are summarised in the table. Improvement was assessed by two observers (JEN and DY), who consecutively measured the circumference and estimated the severity as well as the extent of subcutaneous induration of the affected segment; significant reduction of the circumference and normalisation of the palpatory findings were considered to be an indication of complete recovery (100\%), while partial improvement was estimated and expressed as a percentage.

\section{Case histories}

CASE 1

The patient's clinical course has been previously described in detail. ${ }^{9}$ Briefly, the 70 year old patient, who was under observation for a
Bnai Zion Medical Center and the Faculty of Medicine, Technion, Israel Institute of Technology, Haifa, Israel Department of Medicine A J E Naschitz D Yeshurun

Rheumatology Service I Rosner

Department of Surgery B

J E Abrahamson

Institute of Pathology

I Misselevitch

J H Boss

Correspondence to:

Dr J E Naschitz,

Department of Medicine A, Bnai Zion-Medical Center, Bnai Zion-Medical Center,
PO Box 4940, Haifa 31480, Israel.

Accepted for publication 3 November 1989
Clinical and laboratory data

\begin{tabular}{|c|c|c|c|}
\hline & Case 1 & Case 2 & Case 3 \\
\hline $\begin{array}{l}\text { Age (years) } \\
\text { Sex }\end{array}$ & $\begin{array}{c}70 \\
\text { Male }\end{array}$ & $\begin{array}{l}54 \\
\text { Female }\end{array}$ & $\begin{array}{l}34 \\
\text { Male }\end{array}$ \\
\hline \multicolumn{4}{|l|}{ Cutaneous features } \\
\hline Site & Forearms and calves & Thighs and calves & $\begin{array}{l}\text { Abdomen, arm and } \\
\text { forearm }\end{array}$ \\
\hline $\begin{array}{l}\text { Shape } \\
\text { Type }\end{array}$ & $\begin{array}{l}\text { Diffuse } \\
\text { Tight induration }\end{array}$ & $\begin{array}{l}\text { Diffuse } \\
\text { Puffy to firm }\end{array}$ & $\begin{array}{l}\text { Plaque and linear } \\
\text { Induration and alopecia }\end{array}$ \\
\hline Extracutaneous features & $\begin{array}{l}\text { Pericarditis, colitis, } \\
\text { carpal tunnel syndrome }\end{array}$ & Polyarthritis & None \\
\hline Microscopy of nailfold capillaries & Normal & Normal & $\begin{array}{l}\text { Focal loss, distortion, } \\
\text { and dilatation }\end{array}$ \\
\hline $\begin{array}{l}\text { Blood eosinophils }\left(\times 10^{9} / 1\right) \\
\text { Immunoglobulins }\end{array}$ & $\begin{array}{l}650 \\
\text { Lambda spike }\end{array}$ & $\begin{array}{l}240 \\
\text { Polyclonal increase }\end{array}$ & IgE $820 \mathrm{U} / \mathrm{ml} \|$ \\
\hline \multicolumn{4}{|l|}{ Clinical course: } \\
\hline $\begin{array}{l}\text { Duration (months)* } \\
\text { Onset of regression (months) } \dagger\end{array}$ & $\begin{array}{r}14 \\
2\end{array}$ & $\begin{array}{l}12 \\
1\end{array}$ & $\begin{array}{l}6 \\
2\end{array}$ \\
\hline \multicolumn{4}{|l|}{ Grade of improvement } \\
\hline Cutaneous (\%) 9 & $\begin{array}{r}90 \\
100\end{array}$ & $\begin{array}{r}80 \\
0\end{array}$ & $\begin{array}{l}80 \\
80\end{array}$ \\
\hline $\begin{array}{l}\text { Extracutaneous (\%) } \\
\text { Follow up (months) } \ddagger\end{array}$ & $\begin{array}{r}100 \\
36\end{array}$ & $\begin{array}{l}0 \\
7\end{array}$ & $\begin{array}{l}80 \\
15\end{array}$ \\
\hline
\end{tabular}

${ }^{*}$ Duration refers to time interval between first signs and diagnosis.

tOnset of regression refers to time interval between start of cimetidine treatment and regression of cutaneous lesion by one or more centimetres.

$\ddagger$ Follow up refers to observation period after start of cimetidine treatment.

Percentage of improvement is an estimate of disease at the time of writing compared with that at the time of diagnosis. Normal value $100 \mathrm{U} / \mathrm{ml}$. 
monoclonal gammopathy, developed bilateral carpal tunnel syndrome and brawny induration of the forearms and calves. Peripheral blood eosinophilia and antithyroglobulin antibodies were found. Biopsy specimens showed septal fasciitis and panniculitis with an eosinophil-rich infiltration. Treatment with cimetidine was started. Improvement of skin induration was noted after two months and the eosinophil counts returned to normal, but the patient developed pericarditis and eosinophilic colitis three and eight months, respectively, after the start of treatment. In the absence of other causes the pericarditis and colitis, which remitted within a few weeks, were attributed to the underlying fasciitis-panniculitis syndrome. With long term cimetidine treatment the cutaneous manifestations disappeared almost completely; the thyroid antibodies were no longer detectable.

CASE 2

A 54 year old patient first noticed numbness and swelling of the calves as well as morning stiffness of hand and ankle joints eight months before initial examination. Symmetrical arthritis was observed. A variety of non-steroidal antiinflammatory drugs was taken without benefit. Four months later, at admission to our ward, the legs were swollen and indurated, and symmetrical, non-erosive polyarthritis was noted. Nuclear antibodies and rheumatoid factor were not found. A biopsy specimen showed septal and lobular panniculitis, a fibrotically thickened and mildly inflamed fascia (fig 1),

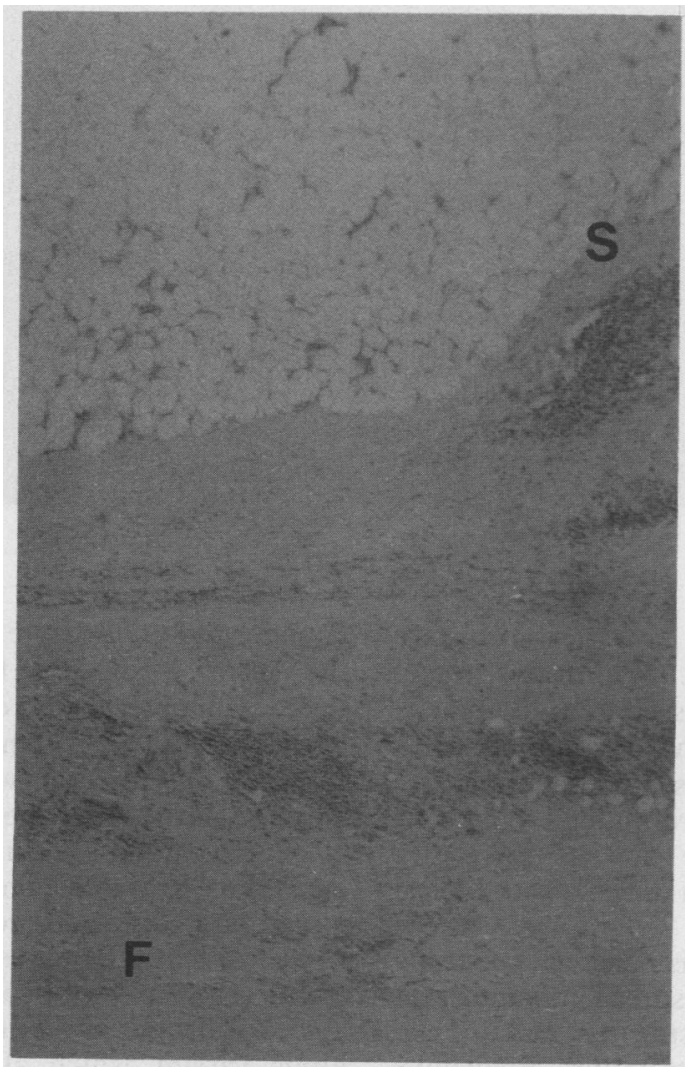

Figure 1 Severely thickened fascia $(F)$, coalescent with a somewhat thickened septum $(S)$. The fascia is composed of dense collagenous connective tissue and contains several foci of mononuclear cell infiltrates. (Haematoxylin and eosin.) lymphocytic phlebitis (fig 2), dermal as well as subcutaneous perivascular, mononuclear cell infiltrates, a rare occluded small vein in the dense collagenous tissue of the thickened subcutaneous septa, and a few epithelioid celled granulomas (fig 3). The inflammatory infiltrate consisted predominantly of lymphocytes with some admixed histiocytes and plasma cells; eosinophils were not evident. Extensive clinical and laboratory work-up and imaging procedures did not show that other organ systems were affected. At this time, the patient was given cimetidine. After four months of treatment the indurations decreased to a considerable extent. As morning stiffness and joint tenderness persisted, prednisone (40 mg daily) was given for 10 days and the articular symptoms (but not the residual skin induration) improved. The patient was still taking cimetidine at the time of writing.

\section{CASE 3}

Two years before presentation the 34 year old patient had a myocardial infarction and was treated with quinidine bisulphate for six months. During the intervening period he was asymptomatic and did not take any drugs. The patient first noticed paraumbilical and forearm skin indurations six and three months, respectively, before admission. He had no fever. The lesions were not painful or tender but enlarged progressively. On admission, a whitish, alopecic, oval and firm lesion, measuring $5 \times 3 \mathrm{~cm}$, was found in the right paraumbilical region. A linear, firm, skin coloured lesion, about $1 \mathrm{~cm}$ in diameter, extended from the radial aspect of the right wrist to the axillary fold. A biopsy specimen of the forearm lesion showed extensive chronic dermatitis, panniculitis, and fasciitis. There was broad-banded collagen fibrosis of the lower dermis with entrapment of the adnexae. The severely thickened subcutaneous septae and fascia contained infiltrates of lymphocytes, plasma cells, and histiocytes as well as many mast cells. The blood vessels were thick walled and a mural, mononuclear cell infiltrate was apparent in many veins. Microscopical examination of the capillary nail bed showed extensive avascular areas as well as occasional aneurysmal dilatation of capillary loops. After treatment with cimetidine the linear induration of the upper extremity disappeared completely within eight months, while the paraumbilical plaque decreased to a size of $3 \times 1.5 \mathrm{~cm}$ and softened. The normal skin colour reappeared and the hair regrew. Repeat microscopical examination of capillaries showed regular capillary loops with occasional avascular areas.

\section{Discussion}

The atypical fasciitis-panniculitis syndrome pertains to the scleroderma syndrome complex, which, by current classification, includes systemic sclerosis, CREST (calcinosis, Raynaud's phenomenon, oesophageal dysmotility, sclerodactyly, telangiectasia) syndrome, localised scleroderma, chemically induced symptoms similar to scleroderma, eosinophilic fasciitis, 
Figure 2 Lymphocytic phlebitis. A normal artery adjacent to a severely affected vein, the lumen of by an intimal cushion, the latter as well as the media and adventitia being heavily infiltrated by $a$

predominantly lymphocytic infiltrate. (Haematoxylin and eosin.) which is subtotally occluded

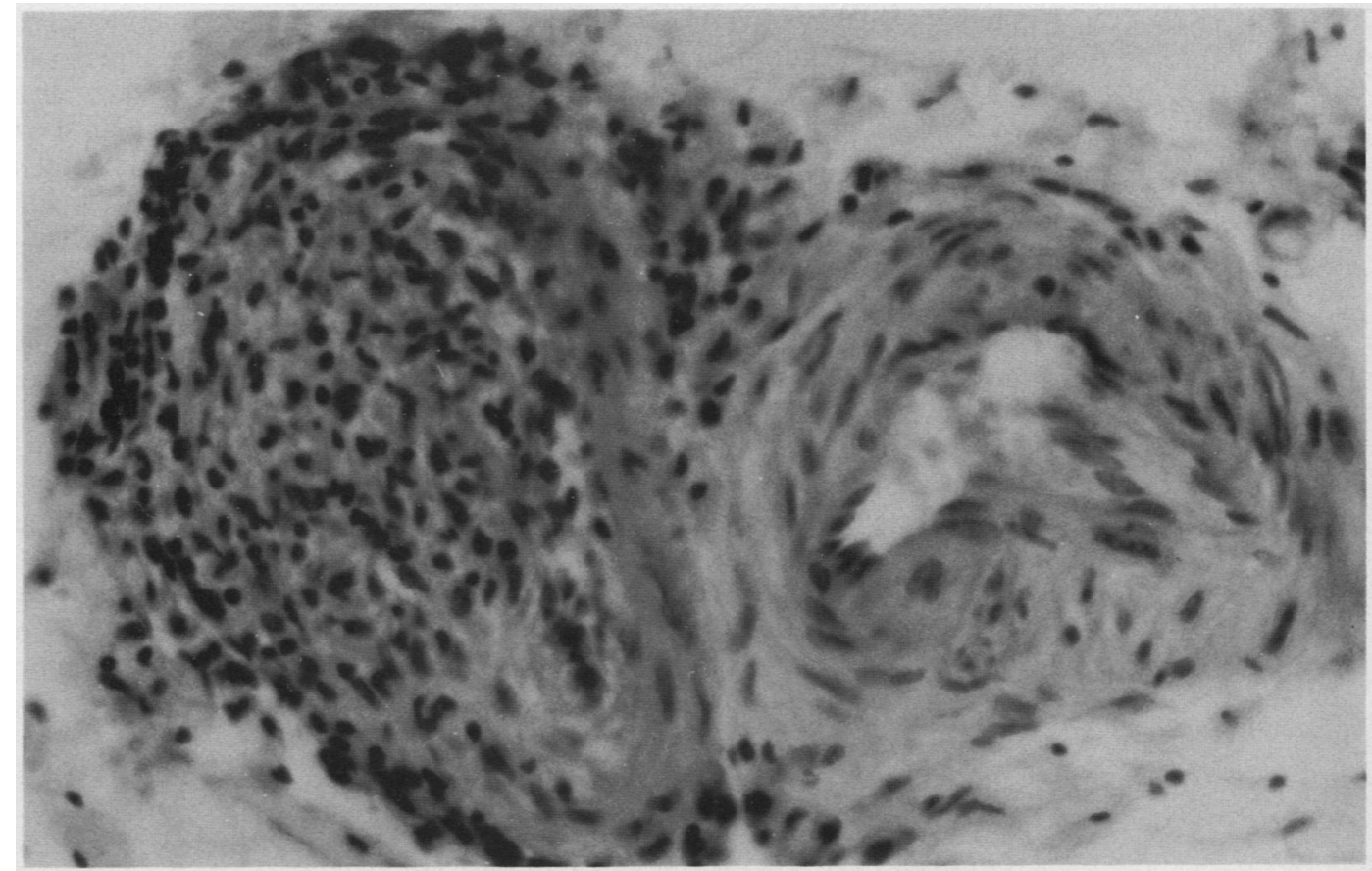

Figure 3 Subcutaneous granuloma. Discrete aggregate of epithelioid histiocytes and lymphocytes in the subcutaneous fat tissue. (Haematoxylin and eosin.)

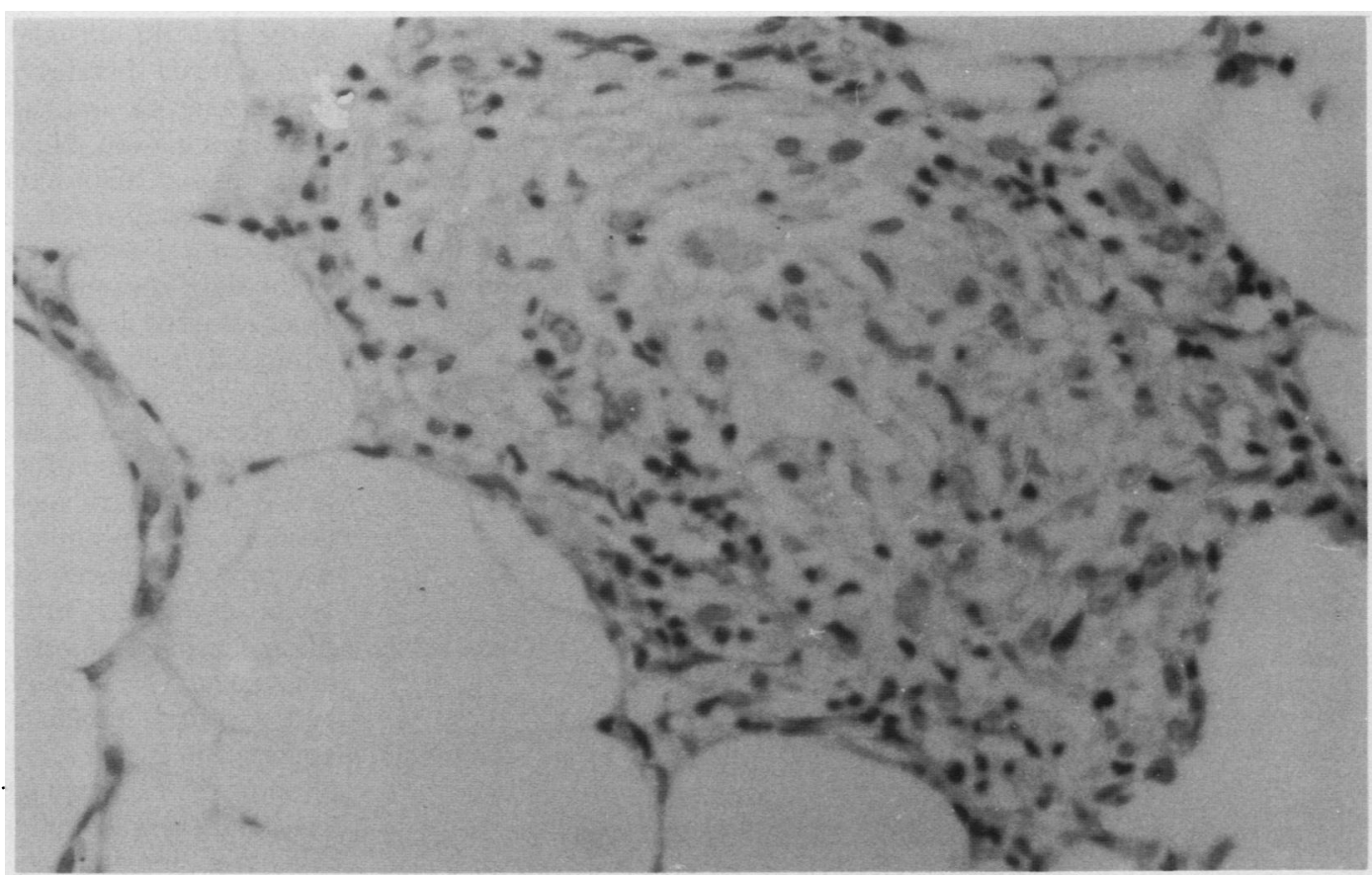

pesudoscleroderma, and a variety of rare scleroderma-like disorders. ${ }^{2}$ Within this framework panniculitis with associated fasciitis is histologically distinct and has been described in eosinophilic fasciitis, localised scleroderma, and lupus erythematosus profundus. ${ }^{1310}$ The clinical diagnosis of any one of the latter conditions is easily made in patients with typical symptoms.

Eosinophilic fasciitis is characterised by symmetrical, usually widespread inflammation and sclerosis of the fascia, subcutis, and dermis, primarily affecting the extremities. Raynaud's phenomenon, ulceration of the finger tips, telangiectasias and visceral disease are rare. Eosinophilia, hypergammaglobulinaemia, and an increased erythrocyte sedimentation rate are the main laboratory findings. ${ }^{13}$ Localised scleroderma presents as either the morphoea or linear variant. The former manifests porcelain coloured indurations with sharp violaceous borders; in the latter there is a band-like, skincoloured induration confined to the limb or facial skin. Raynaud's phenomenon and visceral disease are absent. In contrast with the histologically identical progressive systemic sclerosis, the prognosis of localised scleroderma is favourable. ${ }^{10}{ }^{11}$ Lupus erythematosus profundus is a lupus variant which affects the dermis and subcutis and is histologically similar to eosinophilic fasciitis. The patient presents with well circumscribed, subcutaneous nodules that are 
not tender. Lupus erythematosus profundus frequently occurs as an isolated disorder, but it may be associated with discoid or systemic lupus erythematosus. ${ }^{111}$

In our experience, in a patient with panniculitis-fasciitis the clinical diagnosis may be uncertain because of several atypical features: the concurrent presence of two different dermatological lesions, variable intensities of the cutaneous features, diverse extracutaneous manifestations, and unusual laboratory or capillary microscopical findings. The variability of the clinical picture may give rise to perplexing diagnostic dilemmas. Thus in our first patient, eosinophilic fasciitis evolved in the framework of a multisystem disease ${ }^{9}$ contradicting the dictum that, while involvement of one visceral organ occurs in less than $10 \%$ of cases, several organs being affected is practically unknown. ${ }^{2-4}$ The clinical importance of thyroglobulin antibodies and monoclonal gammopathy in this patient was unclear. Concurrent seronegative polyarthritis and eosinophilic fasciitis, found in our second patient, have rarely been described. ${ }^{2} 1213$ Whether the two are aetiologically related or merely constitute an incidental association cannot be determined at present. In case 2 a few epithelioid cell granulomas and phlebitis were found in the inflamed subcutaneous tissue; though not characteristic of eosinophilic fasciitis, both these findings have been previously described in rare instances. ${ }^{214}$ The plaque-like morphoea and linear scleroderma in our third patient were found simultaneously with severe abnormalities of the nailfold capillaries, which were some distance from the site of the cutaneous lesions. Although such microvascular injury does not characterise localised scleroderma, it is associated with progressive systemic sclerosis. ${ }^{78}$ As the patient's illness does not satisfy any of the American Rheumatism Association's criteria for scleroderma, ${ }^{15}$ the diagnosis of progressive systemic sclerosis cannot be entertained, though the abnormalities of the nailfold capillaries may predict the development of this disease. Moreover, the increased serum IgE concentration and tissue mast cell infiltration are not components of any of the subtypes of scleroderma and add to the lack of definition of the AFPS in this instance. Thus, in conclusion, we propose that a definite diagnosis in these patients is best deferred and a tentative diagnosis of atypical fasciitis-panniculitis syndrome is preferred.

The prognoses of typical fasciitis-panniculitis syndromes are favourable, whereas the outcome of AFPS, as we have presented it, is currently unknown. The treatment of patients with typical eosinophilic fasciitis and localised scleroderma is controversial and the efficacy of any modality of treatment has only recently been questioned. ${ }^{2}$ Initial reports have suggested that eosinophilic fasciitis responds favourably to corticosteroids. ${ }^{14}$ This has not been universally validated, however, and a satisfactory response has been witnessed in less than two thirds of patients. ${ }^{2}$ Other drugs have been tried, including azathioprine, ${ }^{17}$ D-penicillamine, ${ }^{17}$ chloroquine, ${ }^{15}$ and cimetidine. ${ }^{19}$ Because of the small number of reported patients treated with these drugs, the therapeutic efficacy has not been clearly established. Furthermore, the observation that four of five untreated patients in one series improved spontaneously ${ }^{2}$ casts doubt on the value of any modality of treatment.

Our patients' disease improved with cimetidine. We submit that a true therapeutic effect occurred rather than a merely coincidental improvement for the following reasons. Before cimetidine treatment was started the patients' disease progressed for eight to 18 months; while receiving cimetidine, a turning point was evident within one to two months, which interval is considerably less than that usually required for corticosteroids to be effective in similar disorders. ${ }^{2}$ It should be noted that we did not add any anti-inflammatory drugs to the patients' regimen. Similar beneficial effects have been reported in the treatment of eosinophilic fasciitis with cimetidine by others. ${ }^{19-22}$ Four of five patients improved within several days to a few months after starting treatment. Finally, concomitant with the remission of the cutaneous manifestations, extracutaneous abnormalities of the AFPS also improved in our patients. Antithyroid antibodies were no longer detectable (case 1) and nailfold capillary disturbances improved (case 3). Pericarditis and colitis, which developed early in the course of cimetidine treatment (case 1), remitted without additional medication. On the other hand, smouldering polyarthritis (case 2) remained unchanged.

The pharmacological effects of cimetidine on immunologically mediated disorders are at least partly attributed to its interference with the action of histamine on membrane bound $\mathrm{H}_{2}$ receptors of suppressor T lymphocytes. ${ }^{23-25} \mathrm{It}$ is of interest in this context that there was a conspicuous mastocytic infiltration of the lesion in the patient with localised scleroderma. The excellent response of mast cell-associated disorders to $\mathrm{H}_{2}$ antagonists is well known. ${ }^{26}$ Although neither the pathogenetic mechanisms operative in patients with AFPS nor the pathways of the beneficial effects of cimetidine are clear, our observations encourage further trials of this agent in scleroderma-like conditions.

In conclusion, we have described three patients with features of eosinophilic fasciitis or localised scleroderma and certain additional atypical elements. The histological findings of the patients' lesions had fasciitic and panniculitic changes in common. A favourable therapeutic response to cimetidine was observed. We suggest that it is inappropriate to include these cases within the well established nosological entities of eosinophilic fasciitis or localised scleroderma but that it would be more appropriate to categorise them separately as atypical fasciitis-panniculitis syndrome. Our experience indicates that these patients and possibly others with similar disorders may benefit from treatment with cimetidine.

We thank Mr Eliahu Srugo for his photographic assistance.

1 Ackerman B A. Histologic diagnosis of inflammatory skin diseases. A method by pattern analysis. Philadelphia: Lea and Febiger, 1978: 792 .

2 Lakhanpal S, Ginsburg W W, Michet C J, Doyle J A, Moore 
S B. Eosinophilic fasciitis: clinical spectrum and therapeutic response in 52 cases. Semin Arthritis Rheum 1988; 17: response

3 Barnes L, Rodnan G P, Medsger T A Jr, Short D Eosinophilic fasciitis. A pathologic study of 20 cases. $A m \mathcal{J}$ 493-507.

4 Rocco V K, Hurd E R. Scleroderma and scleroderma-like disorders. Semin Arthritis Rheum 1986; 16: 22-69.

5 Shiel W C Jr, Prete P E, Jason M, Andrews B S. Palmar fasciitis and arthritis with ovarian and non-ovarian carcinomas. New syndrome. Am $\mathcal{F}$ Med 1985; 79: 640-4.

6 Pfingsgraff J, Buckingham R B, Killian P J, et al. Palmar fascitis and arthritis with malignant neoplasms: A paraneoplastic syndrome. Semin Arthritis Rherm 1986; 16: $118-25$

7 Rozboril M B, Maricq H D, Rodnan G P, Jablonska S, Bole G G. Capillary microscopy in eosinophilic fasciitis. A comparison with systemic sclerosis. Arthritis Rheum 1983; 26: 617-21.

8 Wong M L, Highton J, Palmar D G. Sequential nailfold capillary microscopy in scleroderma and related disorders. Ann Rheum Dis 1988; 47: 53-61.

9 Naschitz J E, Yeshurun D, Misselevitch I, Boss J H. Colitis and pericarditis in a patient with eosinophilic fasciitis. A contribution to the multisystem nature of eosinophilic fasciitis. I Rheumatol 1989; 16: 688-90.

10 Jablonska S, Rodnan G P. Localised forms of scleroderma. Clin Rheum Dis 1979; 5: 215-41.

11 Winkelmann R K. Panniculitis in connective tissue diseases. Arch Dermatol 1983; 119: 336-44.

12 Rosenthal J. Benson M D. Diffuse fasciitis and eosinophilia with symmetric polyarthritis. Ann Intern Med 1980; 92:

13 Olson N Y, Lindsley C B, Kepes J J. Eosinophilic fasciitis presenting as inflammatory polyarthritis. Pediatrics 1986 78: $512-4$.
14 Moore T L, Zucker J. Eosinophilic fasciitis. Semin Arthritis Rheum 1980; 9: 228-35.

15 Masi A T, Rodinan G P, Medsger T A Jr. Preliminary criteria for the classification of systemic sclerosis (scleroderma) for the classification of system

16 Shulman L E. Diffuse fasciitis with hypergammaglobulinemi and eosinophilia: A new syndrome? $\mathcal{f}$ Rheumatol 1974; 1 (suppl): 46.

17 Nassonova V A, Ivanova M W, Akhnazarova V D. Eosinophilic fasciitis. Review and report of six cases. Scand $\mathcal{f}$ Rheumatol 1979; 8: 225-33.

18 Michet C J Jr, Doyle J A, Ginsburg W W. Eosinophilic fasciitis. Report of 15 cases. Mayo Clin Proc 1981; 56 27-34

19 Solomon G, Barland P, Rifkin H. Eosinophilic fasciitis responsive to cimetidine. Ann Intern Med 1982; 97: 547-9.

20 Loftin E B. Cimetidine and eosinophilic fasciitis. Ann Intern Med 1983; 98: 111-2.

21 Laso F J, Pastor J, De Castro S. Cimetidine and eosinophilic fasciitis. Ann Intern Med 1983; 98: 1026

22 Garcia-Morteo O, Maldonado-Cocco J A, Barreira J C, Barcelo H A. Cimetidine and eosinophilic fasciitis. Ann Interm Med 1984; 100: 318-9.

23 Plaut M, Lichtenstein L M, Henney C S. Properties of subpopulation of $T$ cells bearing histamine receptors. f Clin Invest 1975; 55: 856-74.

24 Rocklin R E. Modulation of cellular immune response in vivo and in vitro by histamine receptor-bearing lymphocytes. f Clin Invest 1976; 57: 1051-8.

25 Hansbrough J F, Zapata-Sirvent R L, Bender E M. Prevention of alterations in postoperative lymphocyte subpopulations by cimetidine and ibuprofen. Am $\mathcal{f}$ Surg 1986 ; 151: $251-5$.

26 Hirschowitz B I, Groake J F. Effect of cimetidine on gastric hypersecretion and diarrhea in systemic mastocytosis. Ann Intern Med 1979; 90: 769-72. 